\title{
QUASISPECIES FEATURE IN SARS-CoV-2
}

\section{Bramhadev Pattnaik ${ }^{1}$, Kuralayanapalya Puttahonnappa Suresh ${ }^{2}$, Rajangam Sridevi ${ }^{2}$, Mahendra P. Yadav ${ }^{3}$, Chandan Shivamallu ${ }^{4}$, Shiva Prasad Kollur ${ }^{5}$, Chandan Dharmashekar ${ }^{4}$, Sharanagouda S. Patil ${ }^{2^{*}}$}

\footnotetext{
${ }^{1}$ Institute of Veterinary Sciences and Animal Husbandry, SoA University, Odisha, India \& Former Director, ICAR-DFMD, Mukteswar, Nainital, India and FAO Ref Centre for FMD in South Asia, Bhubaneswar, Odisha, India

${ }^{2}$ ICAR-National Institute of Veterinary Epidemiology and Disease Informatics (NIVEDI), Bengaluru, Karnataka, India

${ }^{3}$ Former Vice Chancellor, Sardar Vallabhbhai Patel University of Agriculture \& Technology, Meerut, Uttar Pradesh, India

${ }^{4}$ Department of Biotechnology and Bioinformatics, School of Life Sciences, JSS Academy of Higher Education \& Research, Mysuru, Karnataka-570015, India

${ }^{5}$ Department of Sciences, Amrita School of Arts and Sciences, Amrita Vishwa Vidyapeetham, Mysuru, Karnataka, India
}

Received - July 16, 2021; Revision - September 26, 2021; Accepted - October 05, 2021

Available Online - October 30, 2021

DOI: http://dx.doi.org/10.18006/2021.9(5).591.597

\section{KEYWORDS}

FMDV

India

Quasispecies

SARS-CoV-2

\begin{abstract}
Since the identification of the SARS-CoV-2, genus Beta- Coronavirus, in January 2020, the virus quickly spread in less than 3 months to all continents with a susceptible human population of about a 7.9billion, and still in active circulation. In the process, it has accumulated mutations leading to genetic diversity. Regular emergence of variants of concern/significance in different ecology shows genetic heterogeneity in the base population of SARS-CoV-2 that is continuously expanding with the passage of the virus in the vast susceptible human population. Natural selection of mutant occurs frequently in a positive sense (+) singlestranded (ss) RNA virus upon replication in the host. The Pressure of sub-optimal levels of virusneutralizing antibodies and also innate immunity influence the process of genetic/ antigenic selection. The fittest of the mutants, that could be more than one, propagate and emerge as variants. The existence of different lineages, clades, and strains, as well as genetic heterogeneity of plaque purified virus population, justifies SARS-CoV-2 as 'Quasispecies' that refers to swarms of mutant sequences generated during replication of the viral genome, and all mutant sequences may not lead to virion. Viruses having a quasispecies nature may end up with progressive antigenic changes leading to antigenic plurality that is driven by ecology, and this phenomenon challenges vaccination-based control programs.
\end{abstract}

* Corresponding author

E-mail: sharanspin13@gmail.com (Sharanagouda S. Patil)

Peer review under responsibility of Journal of Experimental Biology and Agricultural Sciences.

Production and Hosting by Horizon Publisher India [HPI] (http://www.horizonpublisherindia.in/).

All rights reserved.
All the articles published by Journal of Experimental Biology and Agricultural Sciences are licensed under a Creative Commons Attribution-NonCommercial 4.0 International License Based on a work at www.jebas.org.

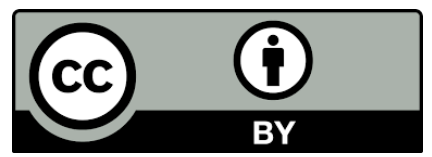




\section{Introduction}

'Quasispecies' is described as mutant clouds comprising of a population of a virus comprising of a large number of genomic variants (Domingo et al, 2012; Domingo \& Perales, 2019). Inside infected cells, a parent virion RNA molecule seldom produces daughter RNA of identical nucleotide sequence, and this occurs as part of the biology of mRNA sense viruses. This variation in the nucleotide sequence in form of substitution/deletion is consequent to error(s) during copying of template/parent RNA molecule by viral RNA-dependent-RNA-polymerase. The significance of a mutant genome sequence, beyond phylogenetic and evolutionary analyses, lies with the existence of matching mutant virions Mutant virus populations with non-identical genome continuously generate due to error-prone viral RNA genome replication, and the spectrum of mutants in a virus population, either plaque purified or not, vary with the progress in virus replication and subsequent selection process that is influenced by ecology comprising of host, environment/ landscape and the virus itself (Domingo \& Perales, 2019). Viruses restrict themselves by either eliminating the host or immunizing the host following primary infection. Such natural restriction in controlling the virus population is usually breached by the emergence of variants that vary in major immunogenic domains. This has been the reason for the second wave of Covid19 in India and elsewhere when many variant virus populations with antigenic dissimilarity have been identified.

\section{Human CoVs}

Human respiratory sickness caused by coronavirus was identified in 1962 (Habas et al., 2020). There are seven species of hCoV, which include $\alpha-\mathrm{CoVs}$ of HCoV-NL63 \& 229E, $\beta$-CoVs of HCoVOC43, HKU1, SARS-CoV-1 and 2, and MERS-CoV. HCoV229E, -OC43, -NL63, and HKU1 are distributed globally. Even though $\mathrm{HCoVs}$ have been identified to create epidemics every 2-3 years with a significant risk of reinfection, there is a scarcity of data on the epidemiology and clinical symptoms of these four HCoVs around the world (Phelan et al., 2020; Ye et al., 2020).

\section{The Coronavirus disease- 2019 (Covid-19)}

Consequent to the steady transboundary transmission of an emerging Coronavirus, SARS-CoV-2, since December 2019 from Wuhan, PRC, causing highly transmissible respiratory disease, named as Covid-2019, in humans across the world (first Covid-19 case in India was detected on 30 January 2020), the World Health Organization (WHO of the UN) declared' Covid-19 pandemic on March 12, 2020 (Li et al., 2020a; Pattnaik \&Yadav, 2020; Platto et al., 2021). The real-time reverse transcriptase-polymerase chain reaction (rRT-PCR) targeting multiple virus genes (E, N, RdRpetc) is the gold standard method for detection of SARS-CoV-2 with variable sensitivity that primarily depends on virus load in the clinical sample, and duration and severity of clinical disease (Corman et al., 2020; Wang et al., 2020a; Li et al., 2020b). During sampling from nostrils and throat or elsewhere, the stage of infection in the individual is largely unknown. Spot antigen test is also being used as a point-of-care (POC) test, and negative samples are subjected to rRT-PCR for the nucleic acid test (NAT). Antibody (IgM and $\operatorname{IgG}$ ) tests are also in use for retrospective diagnosis. NAT positivity is taken as an active infection. There has been NAT positivity with no clinical sickness; also, NAT negativity with respiratory sickness. Radiological examination of the chest by computerized tomography (CT) of patients with suspected SARS-CoV-2 infection is highly sensitive in arriving at a clinical decision based on the degree of lung pathology (Inui et al., 2020; Yang et al., 2020). The Dutch Radiological Society developed the 'COVID-19 Reporting and Data System' (CORADS) that combines chest CT results, clinical data, and NAT results (Prokop et al., 2020; Zayed et al., 2021). Pulmonary pathology is not exclusive to Covid-19, and immunohistochemistry is required to diagnose SARS-CoV-2 infection.

There is no specific treatment for Covid-19, however chemotherapeutic compounds like Remdesvir/ Veklury (ATP analog), Flavipiravir (pyrazine), aminoquinoline, etc., have been used selectively (Majumder \& Minko, 2021). In treatment, though ACE2 enzyme inhibitors and receptor blockers (ARBs) have been used in cardiovascular diseases; but increase in expression of ACE2 receptors on cells following treatment with inhibitor/blocker has been observed (Albini et al., 2020). The use of live attenuated vaccines of Polio, MMR, and BCG (bacillus Calmette-Guerin) could boost non-specific immunity (NSI)/ innate immunity and help in reducing the severity of Covid-19 (Majumder \& Minko, 2021).

\section{The virus}

The SARS-CoV-2 is a Sarbecovirus in the Genus betaCoronavirus $(\beta-\mathrm{CoV})$. Like any other $\mathrm{CoV}$, the genome of SARS-CoV-2 is $(+)$ ssRNA (mRNA sense) of $<30 \mathrm{~kb}$ with 5 ' cap, 3'- poly(A) tail (Pattnaik \& Yadav, 2020). The organization of the viral RNA genome is $5^{\prime}$ cap-L-UTRs-polymerase-SpikeEnv-Membrane-Nucleocapsid-3'UTR-poly(A) (Lu et al., 2020). There are 14 open reading frames (ORFs) in the viral RNA genome, that encode 4 structural proteins of the spike (S), envelope (E), membrane/matrix (M), and nucleocapsid $(\mathrm{N})$, and 16 non-structural proteins (NSPs; from proteolytic processing of polyproteins pp1A and 1ab). The structural genes are interspaced with 9 accessory genes; ORFs 3a, 3b, 6, 7a, 7b, 8, $9 \mathrm{~b}, 9 \mathrm{c}$, and 10 , and the accessory proteins are essential for virus replication, pathogenesis, and virus- morphogenesis processes (Thomas, 2021). Six of the NSPs, viz., 3,9,10,12,15, and 16 are essential in virus replication (Krichel et al., 2020). The S glycoprotein is a transmembrane that binds through residues in 
the Receptor Binding Domain (RBD; in S1 domain) to ACE2 expressed on cells of most human organs. The host TMPRSS2 facilitates membrane fusion with the involvement of the S2 domain of the $\mathrm{S}$ glycoprotein. There is a similarity as well as distinction in amino acid composition in RBD between SARSCoV-1 and -2 (Wan et al. 2020), as both the virus use ACE2 receptor (Hofmann et al., 2020; Wang et al., 2020b). Six different amino acid residues in the RBD are critical in the attachment of the virus to the ACE2 receptor, viz., $\mathrm{Leu}^{455}, \mathrm{Phe}^{486}$, $\mathrm{Gln}^{493}, \mathrm{Ser}^{494}, \mathrm{Asn}^{501}$, and $\mathrm{Tyr}^{505}$ in SARS-CoV-2, and in contrast $\mathrm{Tyr}^{442}, \mathrm{Leu}^{472}, \mathrm{Asn}^{479}, \mathrm{Asp}^{480}, \mathrm{Thr}^{487}$ and $\mathrm{Tyr}^{4911}$ in SARS-CoV-1 (Mohamadian et al., 2020). Both the SARS-1 and -2 viruses are antigenically distinct and different. Highly antigenic epitopes in RBD had A348V, V367F, and A419S (Singh et al., 2020). There was attenuation of SARS-CoV-2 upon deletion of 30 amino acid residues in the S1-S2 junction of S glycoprotein (Lau et al., 2021). Deletion of 382 nucleotides in the accessory protein ORF8 ( $\triangle 382$ variant of SARS-CoV-2) is associated with mild disease (Young et al., 2020). The $\mathrm{N}$ protein attaches to the viral RNA during the morphogenesis of new virion particles and also contributes to immune evasion by the virus ( $\mathrm{Mu}$ et al., 2020). The $\mathrm{M}$ protein is conserved and in association with $\mathrm{N}$ protein and accessory proteins, $3 \mathrm{a}$ and $7 \mathrm{a}$ facilitate the budding of new virion particles (Roy et al., 2020; Ysrafil, 2020). The E protein facilitates virion maturation and releases from infected cells (Naqvi et al. 2020). Globally, NSP1/NSP2 and ORF7a/3a are the most mutable genes of SARS-CoV-2 (Roy et al., 2020). Both the NSPs and ORF7a and ORF3a are involved in virus replication (Bianchi et al., 2021; Thomas, 2021).

\section{Variations in the genome}

The $\mathrm{S}$ gene is variable in the nucleotide sequence, and the virion surface S glycoprotein determines host susceptibility. Mutations and evolution of the Spike gene have been elaborated (Winger \& Caspari, 2021). The most dominant transition and trans-version in the $\mathrm{S}$ gene across the globe were $\mathrm{C} \rightarrow \mathrm{U}$ and $\mathrm{G} \rightarrow \mathrm{U}$ (Roy et al., 2020). The $S$ protein substitution $D^{614} \rightarrow G$ was the first major event in the mutation and evolution of SARS-CoV-2 in the COVID-19 pandemic (Korber et al., 2020; Plante et al., 2020;
Yurkovetskiy et al. 2020). This substitution is located in a B-cell epitope in the $\mathrm{S} 1$ domain that classified the SARS-CoV-2 sequences in 2 subtypes, viz. SARS-CoV-2a and $-2 b$, having amino acid residues D614 and G614 respectively. Lineages of SARS-CoV-2b have spread the world over. Both the subtypes differ in immunogenicity, and subtype $2 b$ is reported to be less immunogenic compared to subtype $2 \mathrm{a}$, the parent virus. This evolution possibly made the host hypo-responsive so that the virus could persist in the human population (Kim et al., 2020). Further G614 increased the stability of the virion and has dominated the global Covid-19 scenario. Mutants with mutations around the ACE2 binding site of the virus are in circulation (http://covglue.cvr.gla.ac.uk; https://www.gisaid.org). Naturally occurring mutations in the S gene at positions E484, F490, Q493, and S494 reduced binding of the virus to the Mabs C121 and C144, and mutations at R346, N439, N440, K444, V445, and G446 lead to reduced affinity to the Mab C135 (Robbiani et al., 2020; Baum et al., 2020). This observation shows the presence of virus populations differing in epitope profile. The selection of neutralization escape mutants in vivo will depend upon the concentration and affinity of the neutralizing antibodies (Weisblum et al., 2020).

Several clades and Spike variants have evolved during the pandemic in different countries., viz., Alpha (B.1.1.7; U.K.), Beta (B.1.351; South Africa), Gamma (P.1; Brazil and Japan), Delta (B.1.617.2; India), Delta Plus $\left(\mathrm{K}^{417} \rightarrow \mathrm{N}\right)$, Epsilon (B.1.429 and B.1.427), Kappa (B.1.617.1; India), and Eta (B.1.525), etc. An S variant with substitution $\mathrm{N}^{501} \rightarrow \mathrm{Y}$ and deletion of histidine and valine codons at positions 69 and 70, were identified in the UK (Tang et al., 2020). The worldwide prevalence of clade B.1.617 was followed by the generation of its variant strains of Kappa $(\kappa)$, Delta ( $\delta$ ), and Delta plus (Figure 2).

Several non-synonymous mutations were detected in the transmembrane and C-terminus domains of the E protein (Hassan et al., 2020). Recurrent non-synonymous mutations are linked to adaptation in humans (vanDorp et al., 2020). Several sites of variation in ORFs $1 \mathrm{a}, 1 \mathrm{~b}, \mathrm{~S}, 3 \mathrm{a}, \mathrm{M}, 8$, and $\mathrm{N}$ indicate elective mutations in the virus (Wang et al., 2020c).

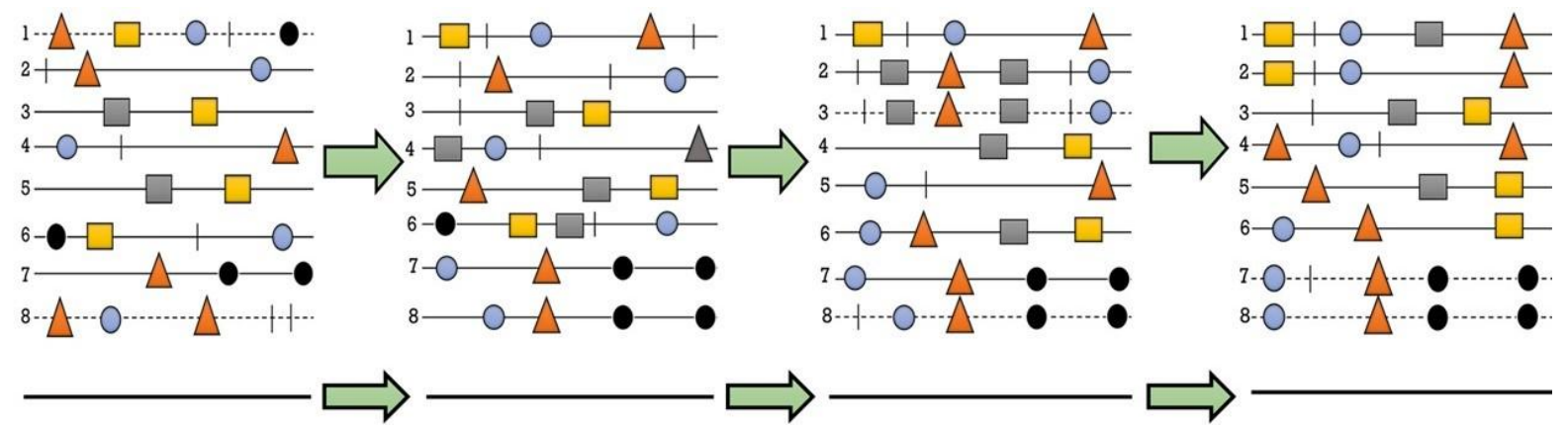

Figure 1 Representation of the evolution (change in composition) of a viral quasispecies (modified from the source: Domingo et al., 2012)

Journal of Experimental Biology and Agricultural Sciences http://www.jebas.org 


\section{Conclusion and Future Prospects}

There is a continuous evolution of SARS-CoV-2 leading to SNP variants and many lineages. SARS-CoV-2 has undergone strong selection pressure over a short period since December 2019. Forces of selection (fitness is the criterion) by the host immune system during replication of the virus and its transmission between hosts play an important role (Roy et al., 2020). The virus also undergoes genetic evolution due to mutations accruing over time and space, producing variants differing from the parent strain(s). The mutation is independent of the fitness of the parent and mutated genome; evolution rate includes time factor. A comprehensive investigation of thousands of SARS-CoV-2 genome sequences identified $>1000$ mutations. Virus strain having less sensitivity to neutralizing antibodies in the immunosuppressed patients was identified. The asymmetric antigenic relationship observed between strains (Yadav et al., 2021) is of epidemiological significance. The phenomenon of quasispecies in foot and mouth disease virus (FMDV; Aphthovirus genus) that has (+) ssRNA (mRNA sense) of about $8.5 \mathrm{~kb}$ with 5' -cap, 3'- poly(A) tail has been described, where even virion population in a purified plaque is genetically heterogeneous (Figure 1). CoVs have a higher mutation rate $(0.44-2.77 \times 10-2$ per site per year) compared to the Foot-and-mouth disease virus $(6 \times 10-3$ per site per year), though both have (+) ss RNA genome. Plaque purification of SARS-CoV2 in Vero E6 cells revealed genetic variants in small plaques that could not be detected in the original clinical material. This shows that the variants appeared upon replication of the virus. These

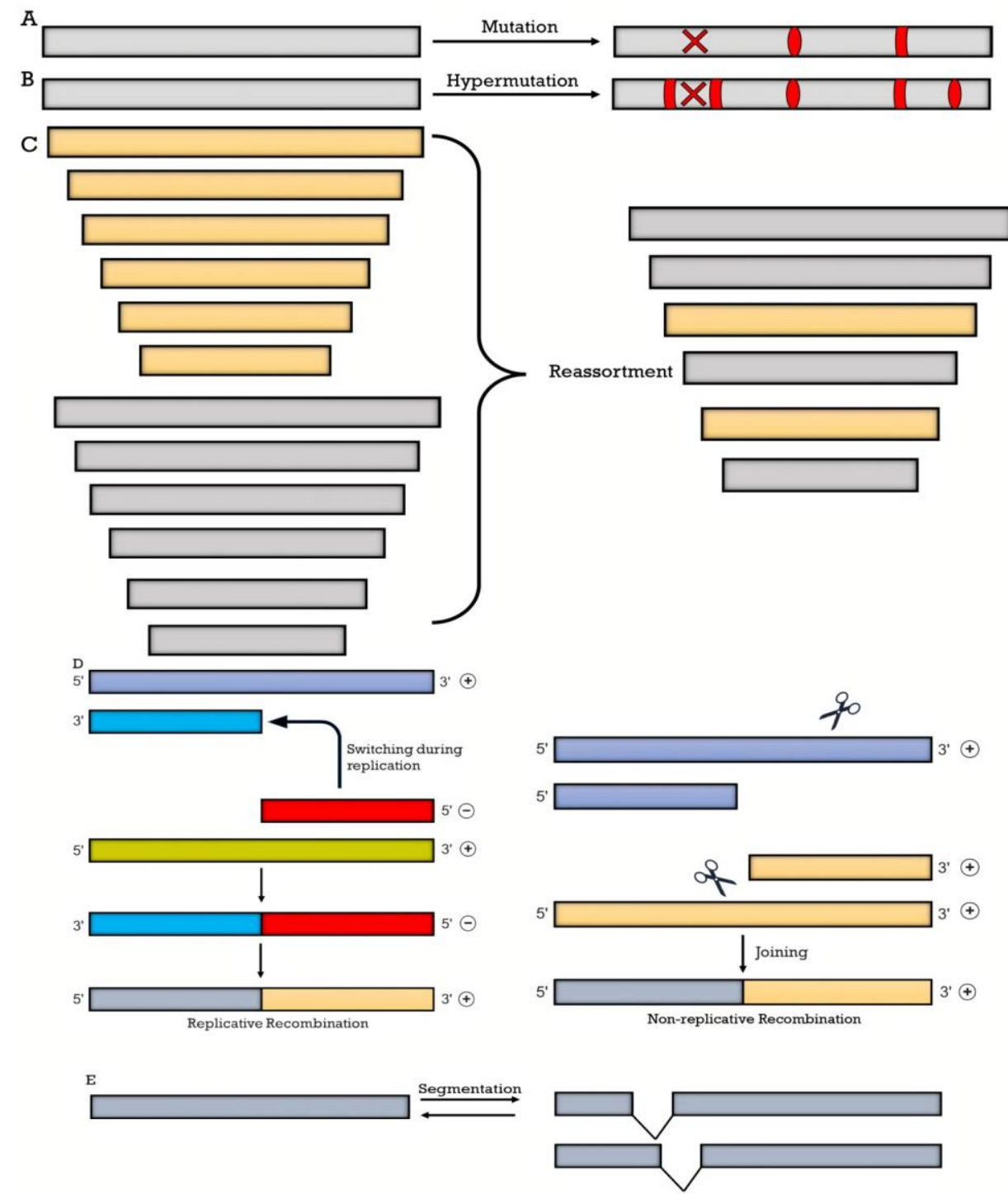

Figure 2 Representation of several types of genetic modifications that can alter the composition of viral quasispecies (modified from the source: Domingo et al., 2012) 
variants were either deletion mutants (15-30 nucleotides deleted) or were having point mutations in the S1-S2 interface. Analysis of 55,189 SARS-CoV-2 sequences identified 2175 sequences having non-synonymous mutations in the Spike gene. The frequency of variation varied from 5.48 in coding regions to 6.96 in the noncoding regions (Cao et al., 2021). These observations support quasispecies in SARS-CoV-2. Despite the ongoing global mass vaccination program, the emergence of new a variant virus threatens control of Covid-19. The proposed future directions are (i) random and regular screening of symptomatic patients for SARS-CoV-2 infection is needed, (ii) regular sequencing and analysis of SARS-CoV-2 isolates should be conducted, (iii) mass awareness about the variants and their effect on human health is to be carried out, (iv) more stress should be given to the vaccination of the entire population and other personal hygienic measures.

\section{Acknowledgment}

Authors thank Dr. V.A. Srinivasan, Director, Board of Directors, IIL, Hyderabad, and Dr. D. T. Mourya, National Institute of Virology, Pune for their critical input in the manuscript. Acknowledge few topics derived from the internet/websites.

\section{Conflict of interest}

None

\section{References}

Albini A, Di Guardo G, McClain Noonan D, Lombardo M (2020) The SARS-CoV-2 receptor, ACE-2, is expressed on many different cell types: implications for ACE-inhibitor- and angiotensin II receptor blocker-based cardiovascular therapies. Internal and Emergency Medicine 15:759-766.

Baum A, Fulton BO, Wloga E, Copin R, Pascal KE, Russo V, Giordano S, Lanza K, Negron N, Ni M, Wei Y, Atwal GS, Murphy AJ, Stahl N, Yancopoulos GD, Kyratsous CA (2020) Antibody cocktail to SARS-CoV-2 spike protein prevents rapid mutational escape seen with individual antibodies. Science 369: 0831-1018.

Bianchi M, Borsetti A, Ciccozzi M, Pascarella S (2021) SARSCov-2 ORF3a: Mutability and function. The International Journal of Biological Macromolecules 170: 820-826.

Cao C, He L, Tian Y, Qin Y, Sun H, Ding W, Gui L, Wu P (2021) Molecular epidemiology analysis of early variants of SARS-CoV-2 reveals the potential impact of mutations P504L and Y541C (NSP13) in the clinical COVID-19 outcomes. Infection, Genetics and Evolution 92:104831.

Corman VM, Landt O, Kaiser M, Molenkamp R, Meijer A, Chu DKW, Bleicker T, Brünink S, Schneider J, Schmidt ML,
Mulders DGJC, et al. (2020) Detection of 2019 novel coronavirus (2019- nCoV) by real-time RT-PCR. Euro Surveill 25:2000045.

Domingo E, Perales C (2019) Viral quasispecies. PLoS genetics 15: e1008271.

Domingo E, Sheldon J, Perales C (2012) Viral Quasispecies Evolution. Microbiology and Molecular Biology Reviews 76: 159 -216 .

Habas K, Nganwuchu C, Shahzad F, Gopalan R, Haque M, Rahman S, Majumder AA, Nasim T (2020) Resolution of coronavirus disease 2019 (COVID-19). Expert review of antiinfective therapy 18:1201-1211.

Hassan SS, Choudhury PP, Roy B (2020) SARS-CoV2 envelope protein: non-synonymous mutations and its consequences. Genomics 112: 3890-3892.

Hofmann M, Kleine-Weber H, Schroeder S, Kruger N, Herrler T, Erichsen S, Schiergens TS, Herrler G, Wu NH, Nitsche A, Muller MA, Drosten C, Pohlmann S (2020) SARS-CoV-2 Cell entry depends on ACE2 and TMPRSS2 and is blocked by a clinically proven protease inhibitor. Cell 181: 271-280.

Inui S, Fujikawa A, Jitsu M, Kunishima N, Watanabe S, Suzuki Y, Umeda S, Uwabe Y (2020) Chest CT findings in cases from the cruise ship "diamond princess" with coronavirus disease 2019 (COVID-19). Radiol Cardiothorac Imaging 2: e200110.

Kim SJ, Nguyen VG, Park YH, Park BK, Chung HC (2020) A novel synonymous mutation of SARS-CoV-2: is this possible to affect their antigenicity and immunogenicity? Vaccines 8:220.

Korber B, Fischer WM, Gnanakaran S, Yoon H, Theiler J, Abfalterer W, Hengartner N, Giorgi E, Bhattacharya T, Foley B, Hastie KM, Parker MD, et al. (2020) Tracking changes in SARS-CoV-2 spike: evidence that D614G increases infectivity of the COVID-19 virus. Cell 182: 812-827.

Krichel B, Falke S, Hilgenfeld R, Redecke L, Uetrecht C (2020) Processing of the SARS-CoV pp1a/ab nsp7-10 region. Biochemistry Journal 477: 1009-1019.

Lau SY, Wang P, Mok BW, Zhang AJ, Chu H, Lee AC, Deng S, Chen P, Chan K, Song W, Chen Z, To KK, Chan JF, Yuen K, Chen H (2021) Attenuated SARS-CoV-2 variants with deletions at the S1/S2 junction. Emerging Microbes \& Infections 9: 837-842.

Li X, Wang W, Zhao X, Zai J, Zhao Q, Li Y, Chaillon A (2020a) Transmission dynamics and evolutionary history of 2019-nCoV. Journal Medical Virology 92:501-511. 
Li Y, Yao L, Li J, Chen L, Song Y, Cai Z, Yang C (2020b) Stability issues of RT-PCR testing of SARS-CoV-2 for hospitalized patients clinically diagnosed with COVID-19. Journal Medical Virology 92: 903-908.

Lu R, Zhao X, Li J, Niu P, Yang B, Wu H, Wang W, Song H, Huang B, Zhu N, Bi Y (2020) Genomic characterisation and epidemiology of 2019 novel coronavirus: implications for virus origins and receptor binding. The lancet 395:.565-574.

Majumder J, Minko T (2021) Recent Developments on Therapeutic and Diagnostic Approaches for COVID-19. The AAPS Journal 23:1-22.

Mohamadian M, Chiti H, Shoghli A, Biglari S, Parsamanesh N, Esmaeilzadeh A (2020) COVID-19: Virology, biology and novel laboratory diagnosis. The Journal of Gene Medicine 3: e3303.

Mu J, Xu J, Zhang L, Shu T, Wu D, Huang M, Ren Y, Li X, Geng Q, Xu Y, Qiu Y, Zhou X (2020) SARS-CoV-2encoded nucleocapsid protein acts as a viral suppressor of RNA interference in cells. Scientific China Life Sciences 63:1-4.

Naqvi AAT, Fatima K, Mohammad T, Fatima U, Singh IK, Singh A, Atif SM, Hariprasad G, Hasan GM, Hassan MI (2020) Insights into SARS-CoV-2 genome, structure, evolution, pathogenesis and therapies: structural genomics approach. Biochimica et Biophysica Acta - Molecular Basis of Disease1866:165878.

Pattnaik B, Yadav MP (2020) Covid-19 Pandemic: History, Aetiology, Epidemiology, Vaccinology, and Societal Impact. Indian Journal Comparative Microbiology Immunology and Infectious Diseases 41: 24-41.

Phelan AL, Katz R, Gostin LO (2020) The novel coronavirus originating in Wuhan, China: challenges for global health governance. JAMA 323:709.

Plante JA, Liu Y, Liu J, Xia H, Johnson BA, Lokugamage KG, Zhang X, Muruato AE, Zou J, Fontes-Garfias CR, Mirchandani D, Scharton D, Bilello JP, et al. (2020) Spike mutation D614G alters SARS-CoV-2 fitness. Nature 592:116-121.

Platto S, Zhou J, Wang Y, Wang H, Carafolic E (2021) Biodiversity loss and COVID-19 pandemic: The role of bats in the origin and the spreading of the disease. Biochemical and Biophysical Research Communications 538:2-13.

Prokop M, Van Everdingen W, Van Rees Vellinga T (2020) CORADS: A Categorical CT Assessment Scheme for Patients Suspected of Having COVID-19 Definition and Evaluation. Radiology 296: E97-E104.
Robbiani DF, Gaebler C, Muecksch F, Lorenzi JCC, Wang Z, Cho A, Agudelo M, Barnes CO, Gazumyan A, Finkin S, Ha“gglo“ FT, et al. (2020) Convergent antibody responses to SARS-CoV-2 in convalescent individuals. Nature 584:437-442.

Roy C, Mandal SM, Mondal SK, Mukherjee S, Mapder T, Ghosh W, Chakraborty R (2020) Trends of mutation accumulation across global SARS-CoV-2 genomes: Implications for the evolution of the novel coronavirus. Genomics 112: 5331-5342.

Singh PK, Kulsum U, Rufai SB, Mudliar SR, Singh S (2020) Mutations in SARS-CoV-2 Leading to Antigenic Variations in Spike Protein: A Challenge in Vaccine Development. Journal of Laboratory Physicians 12:154.

Tang JW, Tambyah PA, Hui DS (2020) Emergence of a new SARS-CoV-2 variant in the UK. The Journal of infection 82:e27e28.

Thomas S (2021) Mapping the Nonstructural Transmembrane Proteins of Severe Acute Respiratory Syndrome Coronavirus 2. Journal of Computational Biology. DOI: 10.1089/cmb.2020.0627.

van Dorp L, Acman M, Richard D, Shaw LP, Ford CE, Ormond L, Owen CJ, Pang J, Tan CC, Boshier FA, Ortiz AT (2020) Emergence of genomic diversity and recurrent mutations in SARSCoV-2. Infection, Genetics and Evolution 83:104351.

Wan Y, Shang J, Graham R, Graham R, Baric RS, Li F (2020) Receptor recognition by the novel coronavirus from Wuhan: an analysis based on decade-long structural studies of SARS coronavirus. Journal of Virology 94:e00127-20.

Wang C, Liu Z, Chen Z, Huang X, Xu M, He T, Zhang Z (2020b) The establishment of reference sequence for SARS-CoV-2 and variation analysis. Journal of Medical Virology 92:667-674.

Wang Q, Zhang Y, Wu L, Niu S, Song C, Zhang Z, Lu G, Qiao C, Hu Y, Yuen KY, Wang Q, Zhou H, Yan J, Qi J (2020c) Structural and functional basis of SARS-CoV-2 entry by using human ACE2. Cell 181: 894-904.e9.

Wang W, Xu Y, Gao R, Lu R, Han K, Wu G, Tan W (2020a) Detection of SARS-CoV-2 in different types of clinical specimens. JAMA 323:1843-1844.

Weisblum Y, Schmidt F, Zhang F, DaSilva J, Poston D, Lorenzi JC, Muecksch F, Rutkowska M, Hoffmann H, Michailidis E, Gaebler C, et al. (2020) Escape from neutralizing antibodies by SARS-CoV-2 spike protein variants. eLife 9: e61312.

Winger A, Caspari T (2021) The Spike of Concern-The Novel Variants of SARS-CoV-2. Viruses 13:1002. 
Yadav P, Mohandas S, Sarkale P, Nyayanit D, Shete A, Sahay R, Potdar V, Baradkar, S, Gupta N, Sapkal G, Abraham P (2021) Isolation of SARS-CoV-2 B. 1.1. 28.2 P2 variant and pathogenicity comparison with D614G variant in hamster model. bioRxiv. DOI:10.1101/2021.05.24.445424.

Yang R, Li X, Liu H, Zhen Y, Zhang X, Xiong Q, Luo Y, Gao C, Zeng W (2020) Chest CT severity score: an imaging tool for assessing severe COVID-19. Radiology: Cardiothoracic Imaging 2(2): e200047.

Ye ZW, Yuan S, Yuen KS, Fung SY, Chan CP, Jin DY (2020) Zoonotic origins of human coronaviruses. International Journal of Biological Sciences 16(10): 1686-1697.

Young BE, Fong SW, Chan YH, Mak TM, Ang LW, Anderson DE, Lee CY, Amrun SN, Lee B, Goh YS, Su YCF,
Wei WE, Kalimuddin S, Chai LYA, et al. (2020) Effects of a major deletion in the SARS-CoV-2 genome on the severity of infection and the inflammatory response: an observational cohort study. Lancet 396:603-611.

Ysrafil AI (2020) Severe acute respiratory syndrome coronavirus 2 (SARS-CoV-2): an overview of viral structure and host response. Diabetes and Metabolic Syndrome 14:407-412.

Yurkovetskiy L, Wang X, Pascal KE, Tomkins-Tinch C, Nyalile TP, Wang Y, Baum A, Diehl WE, Dauphin A, Carbone C, Veinotte K, Egri SB, et al. (2020) Structural and functional analysis of the D614G SARS-CoV-2 spike protein variant. Cell 183: 739-751.

Zayed NE, Bessar MA, Lutfy S (2021) CO-RADS versus CT-SS scores in predicting severe COVID-19 patients: retrospective comparative study. The Egyptian Journal of Bronchology 15:13. 